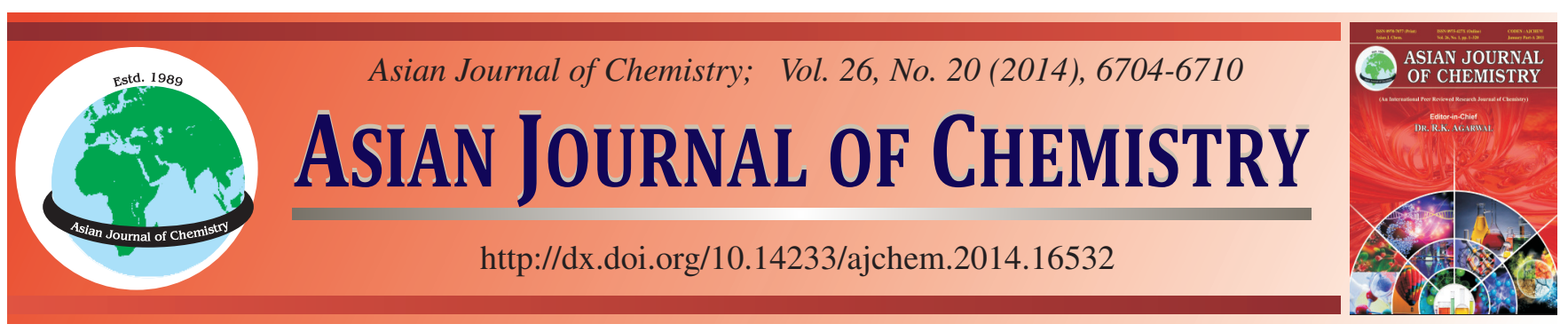

\title{
Optimization of Process Variables in Esterification of iso-Octanol with Acetic Acid using Acid Ionic Liquid as Catalyst
}

\author{
Du Huan, Song Lelian, Tan Zhongqin and XiaOXiang Han*
}

Department of Applied Chemistry, College of Food Science \& Biotechnology Engineering, Zhejiang Gongshang University, Hangzhou, 310035, P.R. China

*Corresponding author: Tel: +86 57188071024 7581; E-mail: hxx74@126.com; han-xx74@163.com

Response surface methodology was successfully applied to optimize esterification of iso-octanol with acetic acid. The effects of various reaction conditions, including reaction time, substrate molar ratio, the amount of catalyst and the amount of water carrying agent were investigated. A Box-Behnken Design was employed to search for the optimal yield of iso-octyl acetate. The analysis confirmed that the reaction time and the amount of water carrying agent were the significant factors affecting the yield of iso-octyl acetate. The coefficient of determination of the model was 0.8922 . Under the optimized conditions, the yield of $i$ so-octyl acetate reached $95.35 \%$, in close agreement with values predicted by the mathematical model. The ionic liquids could be reused five times without noticeable drop in activity.

Keywords: Ionic liquid, Response surface methodology, Isooctyl acetate, Esterification.

\section{INTRODUCTION}

The esterification was conventionally carried out by using homogeneous catalysts such as $\mathrm{H}_{2} \mathrm{SO}_{4}, \mathrm{HF}$ and $\mathrm{H}_{3} \mathrm{PO}_{4}$. It was well-known that these catalysts suffered from inherent problems of corrosiveness, side reactions, environmental hazards, the difficulty in catalyst recovery and its reuse, also the high susceptibility to water. Facing the increasing challenges from both the ecological and economic aspects, organic synthetic chemists are faced with an increasing obligation to optimize their synthetic methods in order to produce the desired product in high yield and selectivity through an environmentally friendly and safe process. Efforts have been made to the development of heterogeneous catalysts such as supported mineral acid $^{1}$, asresins ${ }^{2}$, zeolites ${ }^{3}$ by different groups and heteropoly acids ${ }^{4}$ on the esterification of carboxylic acids. However these processes and these catalysts due to product selectivity, environmental safety, high cost and unstable nature of catalyst could not be used in production centers.

Ionic liquid (IL), a new kind of environmentally benign catalyst, has been receiving a widespread attention for its adjustable physical and chemical properties. Compared to conventional homogeneous and heterogeneous catalysts, ionic liquid especially for acidic ionic liquids demonstrates several advantages: reactions can be carried out under solvent-free condition, the product and ionic liquids can be separated easily.
Such acid ionic liquids have been reported as novel ecofriendly catalysts for some acid catalyzed reactions ${ }^{5-9}$.

Response surface methodology (RSM), a statisticalmathematical method, which was originally described by Box and Wilson (1951), is an effective tool to optimize the process. Response surface methodology usually uses an experimental design such as Box-Behnken design (BBD) to fit an empirical, full second-order polynomial model. The main advantage of it is to reduce the number of experimental trials needed to evaluate multiple variables. Therefore, it is less laborious and time-consuming than other approaches ${ }^{10}$. Response surface methodology is widely applied in the analytical chemistry processes and synthesis processes to determine the effects of several variables and optimize conditions ${ }^{11-13}$.

The aim of the present work is to establish the optimum conditions for the esterification of acetic acid with iso-octanol in a laboratory prepared Brønsted acid functionalized ionic liquid catalyst using the response surface methodology.

\section{EXPERIMENTAL}

Catalyst preparation: $\mathrm{SO}_{3} \mathrm{H}$-functionalized Brønsted acidic ionic liquids were prepared and characterized by IR, NMR, TG and UV-visible spectrophotometer in the laboratory following the procedure outlined in literature ${ }^{14,15}$. All the chemicals were Analytical grade and were used without further purification unless otherwise stated. 
Activity testing: Acetic acid $(10.8 \mathrm{~g}, 0.18 \mathrm{~mol})$, iso-octanol (13.02 g, $0.10 \mathrm{~mol})$, ionic liquid $(0.65 \mathrm{~g})$ and cyclohexane $(10 \mathrm{~mL})$ in a three-necked flask with a stirrer, a water segregator with a reflux condense and a thermometer. The reaction mixture was heated to reflux (oil bath) for desired time and then cooled to room temperature. Chemical analysis of the products was performed by gas chromatography Agilent 6890N GC, equipped with a FID detector and HP-5 capillary column. Reactants and products were identified by comparison with authentic samples. Methyl laurate was used as internal standard.

Response surface methodology: Response surface methodology (RSM) was mainly used to study the relationships between response and a number of input variables and its objective was to optimize the response. In this study, A $2^{4}$ full factorial Box-Behnken design for four independent variables including reaction time $\left(\mathrm{h}, \mathrm{x}_{1}\right)$, alcohol/acid mole ratio $\left(\mathrm{x}_{2}\right)$, the amount of water carrying agent $\left(\mathrm{mL}, \mathrm{x}_{3}\right)$ and the amount of ionic liquid (wt. \%, $\mathrm{x}_{4}$ ) each at three levels was adopted to optimize the yield of iso-octyl acetate and the operation conditions. For each factor, the experimental range and the central point were shown in Table-1a. Selection of these levels was carried out on the basis of results obtained from the single factor study, considering the working conditions limit for each chemical species and minimizing the wastage of the laboratory prepared catalyst by rigorous experimental procedure. The coded values of these factors were obtained according to eqn. (2) below:

$$
\mathrm{x}_{\mathrm{i}}=\frac{\mathrm{X}_{\mathrm{i}}-\mathrm{X}_{0}}{\Delta \mathrm{X}_{\mathrm{i}}}
$$

where $\mathrm{X}_{\mathrm{i}}$ is the coded value of the independent variable, $\mathrm{X}_{\mathrm{i}}$ is the uncoded value of the real variable, $\mathrm{X}_{0}$ is the original value of the centered point and $\Delta \mathrm{X}_{\mathrm{i}}$ is (variable at high level-variable at low level)/2.

\begin{tabular}{lcccc} 
TABLE-1A \\
PARAMETER LEVELS AND CODED VALUES \\
USED IN THE EXPERIMENTAL DESIGN \\
\hline \multirow{2}{*}{ Factors } & Symbol & \multicolumn{3}{c}{ Range and level } \\
\cline { 3 - 6 } & & -1 & 0 & +1 \\
\hline Reaction time (h) & $\mathrm{x}_{1}$ & 1 & 1.5 & 2 \\
Acid/ alcohol molar ratio & $\mathrm{x}_{2}$ & 1.6 & 1.8 & 2.0 \\
Amount of water carrying agent & $\mathrm{x}_{3}$ & 5 & 10 & 15 \\
Amount of catalyst (wt.\%) & $\mathrm{x}_{4}$ & 4 & 5 & 6 \\
\hline
\end{tabular}

Data analysis and ANOVA were performed using the StatEase Design Expert (Version 6.0.5, Stat-Ease. Inc., USA) software. The goodness of fit of the model was evaluated by the coefficient of determination and the analysis of variances.
According to the experimental data, the following quadratic polynomial equation is applied to fit the response variable to a quadratic model:

$$
Y=\beta_{0}+\sum_{i=1}^{k} \beta_{i} x_{i}+\sum_{i=1}^{k} \beta_{i i} x_{i}^{2}+\sum_{j=1}^{k} \beta_{i j} x_{i} x_{i j}+\varepsilon
$$

where $\mathrm{Y}$ and $\mathrm{x}_{\mathrm{i}}$ refer to the predicted response and the coded independent variables or factors, respectively. The term $\beta_{0}$ is the offset term, $\beta_{\mathrm{i}}$ are the linear terms, $\beta_{\mathrm{ii}}$ are the squared terms and $\beta_{\mathrm{ij}}$ are the interaction terms, which are all the regression coefficients, $\mathrm{k}$ is the total number of designed variables, $\varepsilon$ is a random error.

\section{RESULTS AND DISCUSSION}

\section{Effects of operating parameters}

Comparison activity of ionic liquid catalysts: The acidity order of ionic liquids is consistent with their activity order in some acid-catalyzed reactions. It is known that anions have strong interactions with the proton of sulfonic acid. The anion is likely to serve as available acid sites. Hence the acidities and catalytic activities of ionic liquids always depend on the kinds of anions. The catalytic performances of ionic liquid with different anion at certain conditions were given in Table-2. From Table-2, we could find that the ionic liquid with $\mathrm{HSO}_{4}{ }^{-}$ showed the best catalytic activity for esterification. $95 \%$ yield of iso-octyl acetate was obtained. Ionic liquid containing $\mathrm{H}_{2} \mathrm{PO}_{4}{ }^{-}$and $\mathrm{CF}_{3} \mathrm{COO}^{-}$anions showed poor activity. Such a high activity of Brønsted ionic liquid with $\mathrm{HSO}_{4}{ }^{-}$anion has also been reported in the Fischer esterification reaction with other ionic liquids ${ }^{16}$. Table- 2 showed that the order of activity for ionic liquids with different anions was $\left[\mathrm{HSO}_{4}\right]>\left[p-\mathrm{CH}_{3} \mathrm{C}_{6} \mathrm{H}_{4} \mathrm{SO}_{3}\right]$ $>\left[\mathrm{H}_{2} \mathrm{PO}_{4}\right]>\left[\mathrm{CF}_{3} \mathrm{COO}\right]$. It was found that the activity of the acidic ionic liquids was in excellent agreement with their acidity order. Detailed investigations to optimize various reaction parameters were conducted using $\left[\mathrm{HSO}_{3}-\mathrm{pmim}\right] \mathrm{HSO}_{4}$ as catalyst since it was also less toxic and cost effective besides showing high product selectivity.

Optimization of reaction conditions: In order to optimize the reaction conditions of the esterification of iso-octanol with acetic acid, the influence of the reaction time, molar ratio of the reactants, the amount of catalyst and the amount of water carrying agent were studied and the results were shown in Fig. 1.

Reaction time was an important process operation parameter. Fig. 1a presented the effect of the reaction time on the

\begin{tabular}{|c|c|c|c|c|c|}
\hline \multicolumn{6}{|c|}{$\begin{array}{l}\text { TABLE-2 } \\
\text { HAMMETT FUNCTION VALUES OF IONIC LIQUIDS AND THEIR } \\
\text { ACTIVITY FOR ESTERIFICATION OF ACETIC ACID WITH iso-OCTANOL }{ }^{\mathrm{a}}\end{array}$} \\
\hline Ionic liquids & $\mathrm{A}_{\max }$ & {$[\mathrm{I}](\%)$} & {$\left[\mathrm{HI}^{+}\right](\%)$} & $\mathrm{H}_{0}$ & Yield of isooctyl acetate $(\%)^{b}$ \\
\hline$\left[\mathrm{HSO}_{3}-\mathrm{pmim} \mathrm{HSO}_{4}\right.$ & 2.085 & 90.0 & 10.0 & 1.98 & 95.0 \\
\hline$\left[\mathrm{HSO}_{3}\right.$-pmim]PTSA & 2.150 & 93.3 & 6.7 & 2.13 & 90.5 \\
\hline$\left[\mathrm{HSO}_{3}-\mathrm{pmim} \mathrm{H}_{2} \mathrm{PO}_{4}\right.$ & 2.222 & 96.0 & 4.0 & 2.37 & 65.5 \\
\hline$\left[\mathrm{HSO}_{3}-\right.$ pmim $] \mathrm{COOCF}_{3}$ & 2.178 & 94.4 & 5.6 & 2.22 & 59.6 \\
\hline
\end{tabular}
yield of $i$ so-octyl acetate. Results showed that $\left[\mathrm{HSO}_{3}\right.$-pmim $] \mathrm{HSO}_{4}$ 

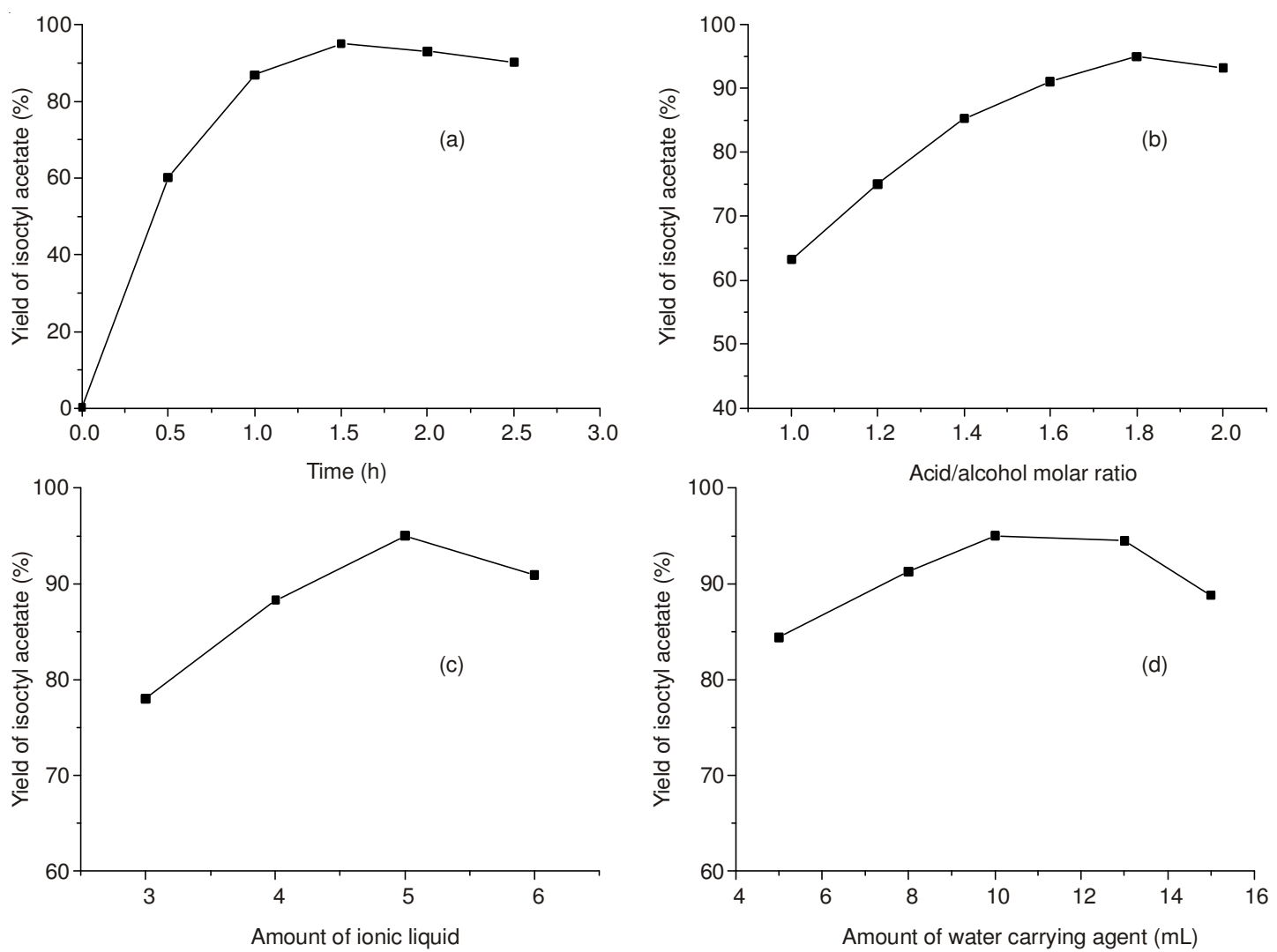

Fig. 1. Effects of four factors on the yield of isooctyl acetate: (a) time, (b) acid/alcohol molar ratio, (c) amount of ionic liquid and (d) amount of water carrying agent

had high catalytic activity due the rapid reduction iso-octanol content at the first $1.5 \mathrm{~h}$. There was no significant improvement at long reaction time higher than $1.5 \mathrm{~h}$. Therefore, $1.5 \mathrm{~h}$ was selected as the optimum reaction time for esterification reaction.

Acetic acid is one is a major component in the pretreatment process via esterification reaction. Its molar ratio significantly affects the conversion of iso-octanol to iso-octyl acetate during the course of reaction. Fig. $1 \mathrm{~b}$ showed the effect of molar ratio on the yield of iso-octyl acetate. The yield of iso-octyl acetate increased with increasing the molar ratio of acid to alcohol. Low loading of acetic acid makes the reaction insufficient to decrease iso-octanol content to the target isooctyl acetate level. 1.8:1 was selected as the optimum value for esterification reaction using $\left[\mathrm{HSO}_{3}\right.$ - $\mathrm{pmim}^{-} \mathrm{HSO}_{4}$ catalyst. Using this molar ratio, the yield of iso-octyl acetate was $95 \%$. Excess molar ratio did not show any improvement in the reduction of iso-octanol content.

The amount of ionic liquids played an important role during the esterification reaction. Finding the optimum amount of catalyst had the priority among all reaction parameters. Fig. 1c showed the effect of the amount of ionic liquids on the yield of $i$ so-octyl acetate. Low amount of catalyst less than 5 wt. \% was insufficient to decrease the iso-octanol content to the target yield iso-octyl acetate. Excessive amount of catalyst did not show any improvement in conversion of iso-octanol to isooctyl acetate. The amount of water carrying agent could control chemical equilibrium reaction system. Thus the poor amount would not achieve better effect of taking water, which could facilitate reaction proceeding. However, further increase of the amount of water carrying agent to $15 \mathrm{~mL}$ resulted in a decrease in yield due to decrease in the concentration of catalyst (Fig, 1d).

Response surface methodology experiments and fitting the models: A Box-Behnken design was employed to design the experiments in this paper due to the reduced number of cumbersome experiments without loss significant information and economize the amount of ionic liquids ${ }^{17}$. According to statistical theory, a Box-Behnken design with four factors consists of 29 experiments, including five replicates at the center point. By the relationship in Table-1a, the statistical combination of the independent variables in coded values and experimental response were presented in Table- $1 \mathrm{~b}$.

When a model selected, an analysis of variance (ANOVA) using Fisher's F-tests, etc., in which the regression sum of square was divided into two parts-that attributed to linear regression and the quadratic model ${ }^{18}$, is calculated to assess whether or not the quadratic model is significant. The ANOVA and the coefficients of the corresponding term were presented in Table-1c. The regression model and variables would be more significant if the Fischer's F-value became larger and the Pvalue became smaller. This study demonstrated that the regression model can be considered statistically significant since the computed F-value (8.28) was much higher than the tabular F-value (3.70) at $1 \%$ confidence level. It indicated that the model was highly significant and the second order polynomial equation was adequate to represent the actual relationship between the response and the variables. The coefficient of 


\begin{tabular}{|c|c|c|c|c|c|}
\hline \multicolumn{6}{|c|}{$\begin{array}{c}\text { TABLE-1B } \\
\text { EXPERIMENTAL DESIGN AND RESPONSE VALUE }\end{array}$} \\
\hline \multirow{2}{*}{$\begin{array}{l}\text { Experimental } \\
\text { no. }\end{array}$} & \multicolumn{4}{|c|}{ Variable and level } & \multirow{2}{*}{$\begin{array}{l}\text { Yield of iso-octyl } \\
\quad \text { acetate }(\%)\end{array}$} \\
\hline & $\begin{array}{l}\text { Reaction time } \\
(\mathrm{h})\end{array}$ & $\begin{array}{c}\text { Acid/alcohol } \\
\text { molar ratio }\end{array}$ & $\begin{array}{c}\text { Amount of water } \\
\text { carrying agent }(\mathrm{mL})\end{array}$ & $\begin{array}{l}\text { Amount of } \\
\text { catalyst }(\%)\end{array}$ & \\
\hline 1 & -1 & -1 & 0 & 0 & 80.05 \\
\hline 2 & -1 & 1 & 0 & 0 & 87.56 \\
\hline 3 & -1 & 0 & 0 & -1 & 79.18 \\
\hline 4 & -1 & 0 & 0 & 1 & 77.09 \\
\hline 5 & -1 & 0 & 1 & 0 & 90.92 \\
\hline 6 & -1 & 0 & -1 & 0 & 69.09 \\
\hline 7 & 0 & 0 & -1 & -1 & 72.58 \\
\hline 8 & 0 & 0 & -1 & 1 & 84.12 \\
\hline 9 & 0 & 0 & 1 & -1 & 86.27 \\
\hline 10 & 0 & 0 & 1 & 1 & 90.88 \\
\hline 11 & 0 & -1 & -1 & 0 & 80.51 \\
\hline 12 & 0 & -1 & 0 & -1 & 74.73 \\
\hline 13 & 0 & -1 & 0 & 1 & 89.74 \\
\hline 14 & 0 & -1 & 1 & 0 & 86.46 \\
\hline 15 & 0 & 1 & 0 & -1 & 82.15 \\
\hline 16 & 0 & 1 & 0 & 1 & 83.05 \\
\hline 17 & 0 & 1 & -1 & 0 & 77.18 \\
\hline 18 & 0 & 1 & 1 & 0 & 88.85 \\
\hline 19 & 1 & 1 & 0 & 0 & 89.30 \\
\hline 20 & 1 & 0 & 0 & -1 & 88.30 \\
\hline 21 & 1 & 0 & -1 & 0 & 85.71 \\
\hline 22 & 1 & 0 & 0 & 1 & 89.73 \\
\hline 23 & 1 & 0 & 1 & 0 & 82.79 \\
\hline 24 & 1 & -1 & 0 & 0 & 84.46 \\
\hline 25 & 0 & 0 & 0 & 0 & 94.37 \\
\hline 26 & 0 & 0 & 0 & 0 & 94.98 \\
\hline 27 & 0 & 0 & 0 & 0 & 95.06 \\
\hline 28 & 0 & 0 & 0 & 0 & 95.07 \\
\hline 29 & 0 & 0 & 0 & 0 & 95.28 \\
\hline
\end{tabular}

TABLE-1C

ESTIMATED REGRESSION COEFFICIENTS AND CORRESPONDING

STATISTICAL $t$ - AND $P$-VALUES FOR YIELD OF iso-OCTYL ACETATE

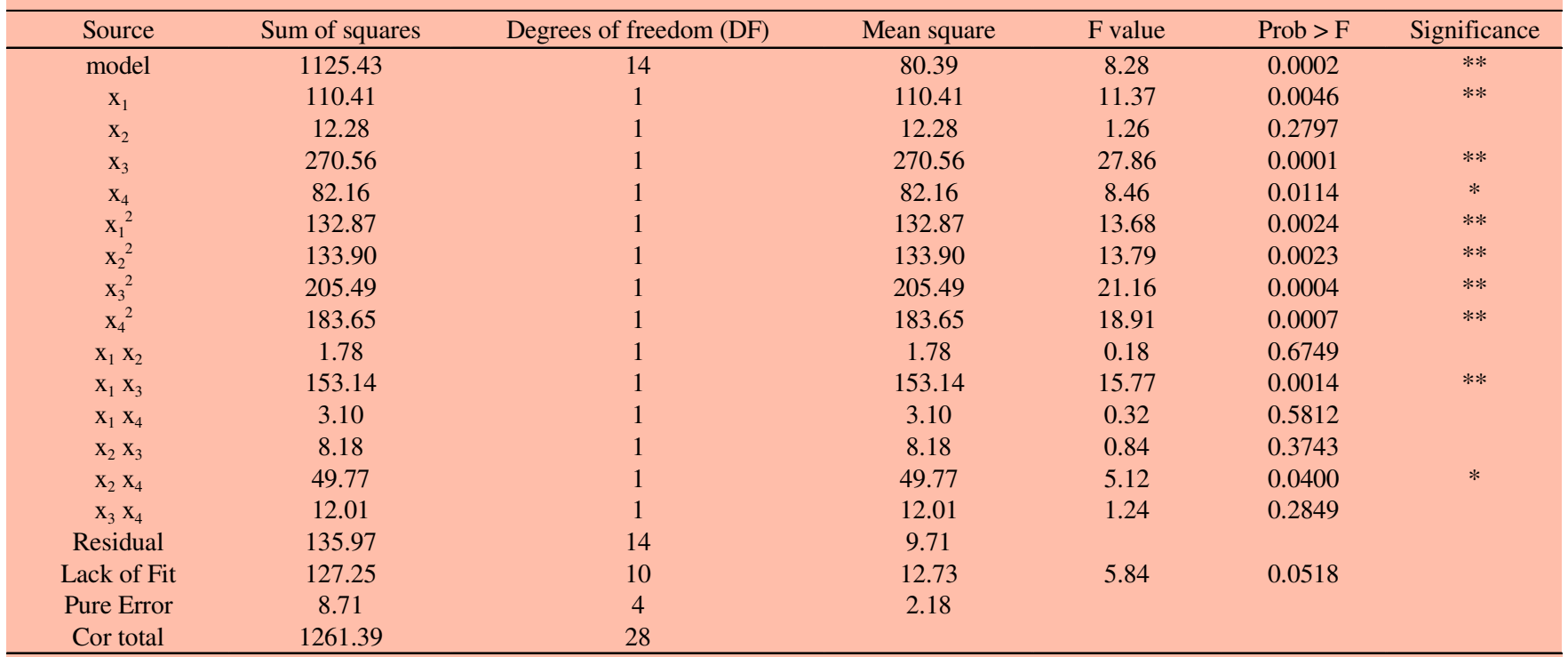

*Represents it is significant ; **Represents it is highly significant

determination $\left(\mathrm{R}^{2}\right)$ of the model was 0.8922 , which indicated the correlation between predicted values and the experimental data points was fitness ${ }^{19}$. The adequate precision of 10.763 was much greater than 4 so that it indicated an adequate signal to noise ratio in this model discrimination. Otherwise, the coefficient of variation $(\mathrm{CV}=3.66 \%)$ with a relatively lower value demonstrated that this model was reproducible. Apart from that, the term of 'Lack of Fit F-value' (5.84) was insignificant implied that model was fitted to all data.

Based on the Table-1b data, a second degree polynomial model was obtained by using eqn. (2) and the fitted equation was shown below by eqn. (3): 
$\mathrm{Y}=-703.97950+88.34367 \mathrm{x}_{1}+497.87333 \mathrm{x}_{2}+8.32347$

$\mathrm{x}_{3}+88.39917 \mathrm{x}_{4}-18.10400 \mathrm{x}_{1}{ }^{2}-113.58750 \mathrm{x}_{2}^{2}-0.22514$

$\mathrm{x}_{3}{ }^{2}-5.32100 \mathrm{x}_{4}{ }^{2}-6.67500 \mathrm{x}_{1} \mathrm{x}_{2}-2.47500 \mathrm{x}_{1} \mathrm{x}_{3}+1.76000 \mathrm{x}_{1} \mathrm{x}_{4}$

$+1.43000 \mathrm{x}_{2} \mathrm{x}_{3}-17.63750 \mathrm{x}_{2} \mathrm{x}_{4}-0.34650 \mathrm{x}_{3} \mathrm{x}_{4}$

where $\mathrm{x}_{1}, \mathrm{x}_{2}, \mathrm{x}_{3}$ and $\mathrm{x}_{4}$ were the coded values of the test variables reaction time, alcohol/acid mole ratio, amount of water carrying agent and amount of catalyst, respectively; Y was the response of yield of iso-octyl acetate. In the equation, positive sign in front of the terms meant it had synergistic effect while negative sign meant it had antagonistic effect.

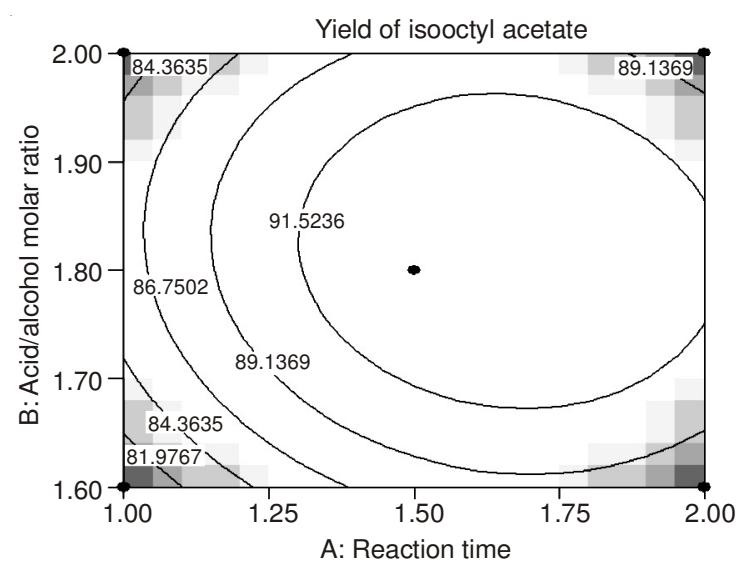

(a)

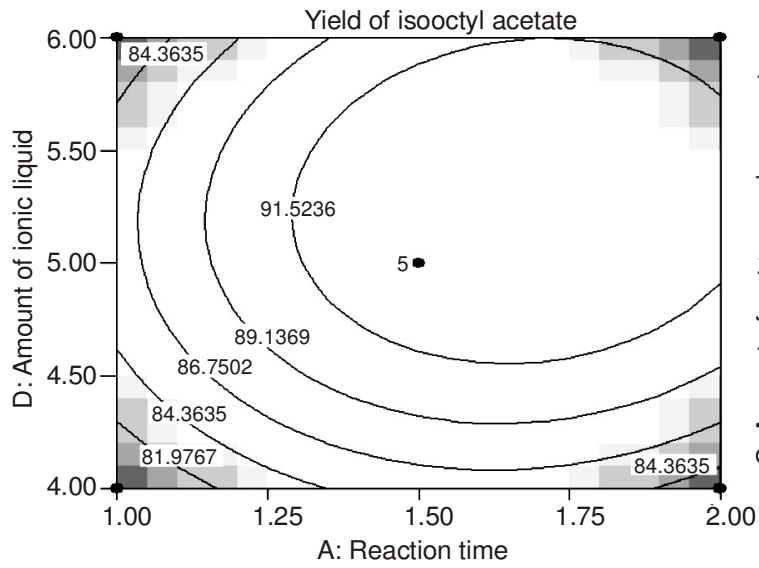

(c)

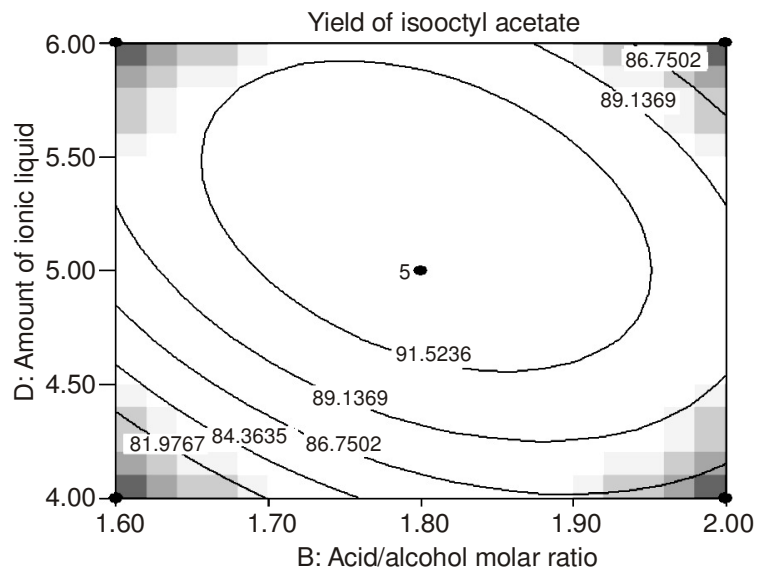

(e)
The contour plots and three dimensional response plots, which were the graphical representation of the relationship between the process parameters and responses, obtained according to the data were presented in Figs. 2 and 3, respectively. The response surface and contour plots showed the relative effects of any two variables when the other variables were kept constant. These plots were used to understand the interaction of two test variables random and determine their optimum levels by holding other test variables constant.

Figs. $2 \mathrm{a}$ and $3 \mathrm{a}$, represented the contour plots and the 3Dplot of the effect of reaction time and alcohol/acid ratio on the

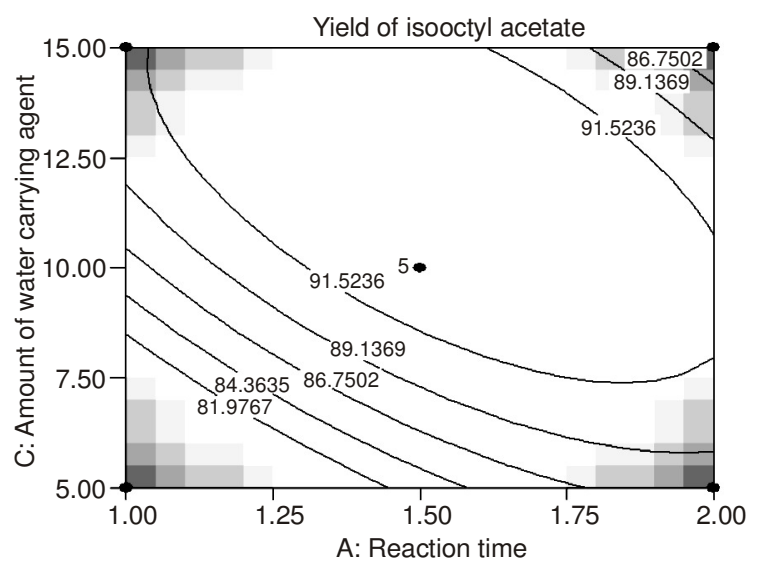

(b)

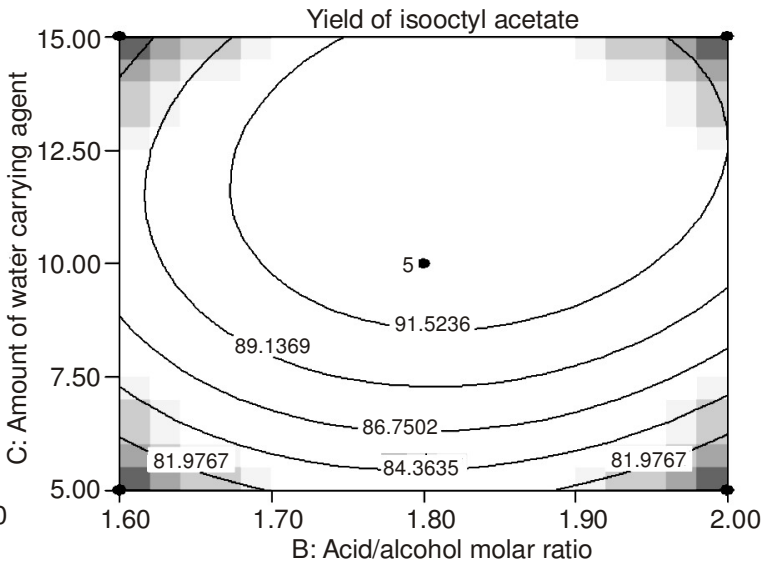

(d)

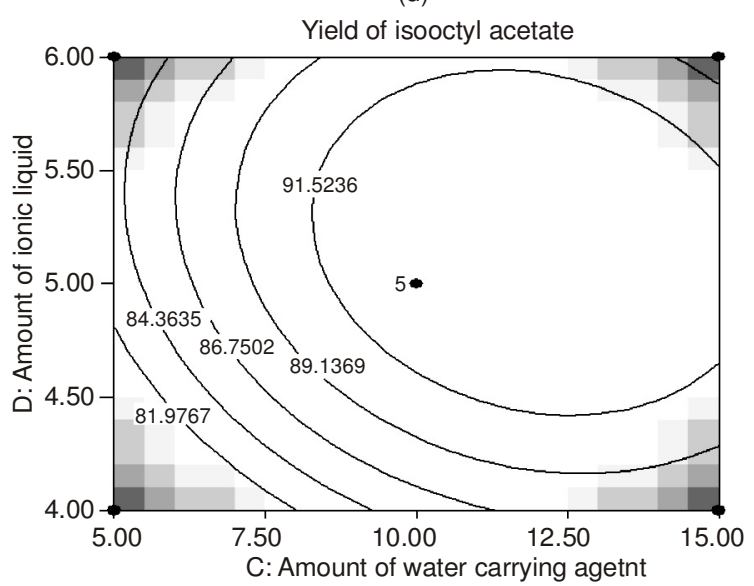

Fig. 2. Contour plots showing the predicted values of yield of isooctyl acetate: effect of reaction time and acid/alcohol molar ratio (a), reaction time and amount of water carrying agent (b), reaction time and amount of ionic liquid (c), acid/alcohol molar ratio and amount of water carrying agent (d), acid/alcohol molar ratio and amount of ionic liquid (e) and amount of ionic liquid and amount of water carrying agent (f) on yield of isooctyl acetate. Other variables are held at constant level 

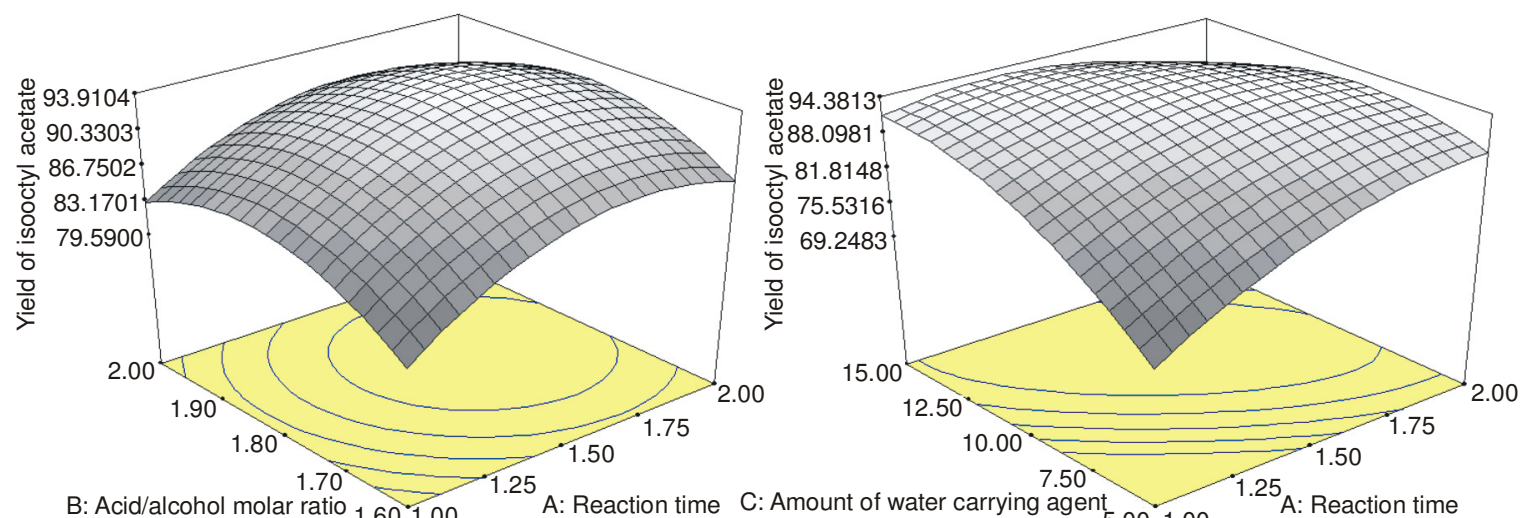

(a)

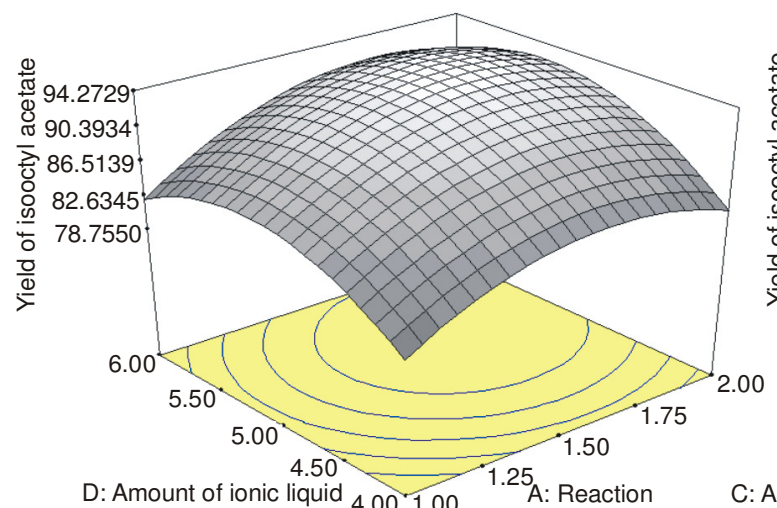

(c)

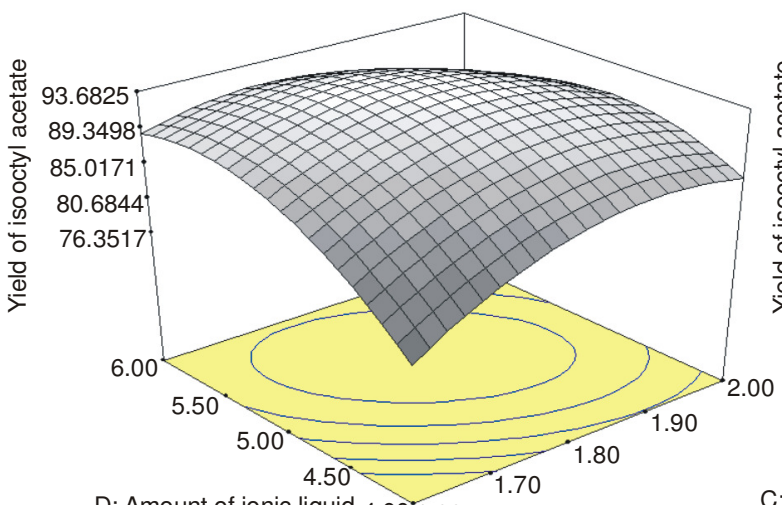

(e)

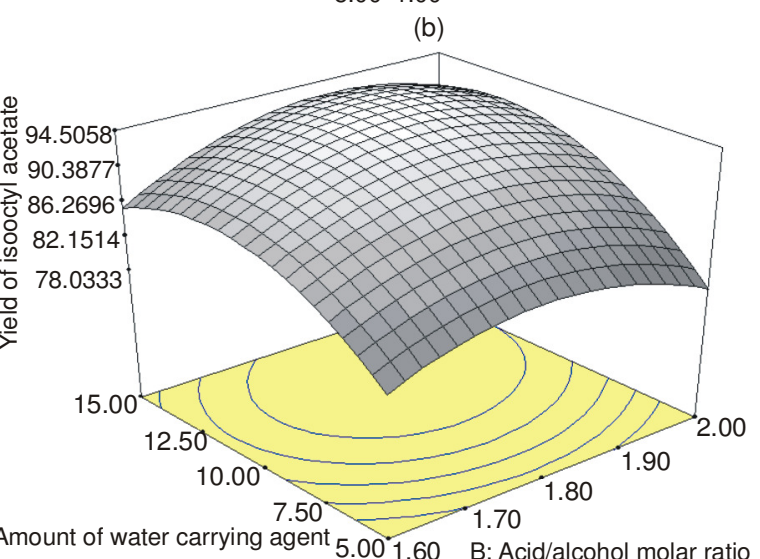

(d)

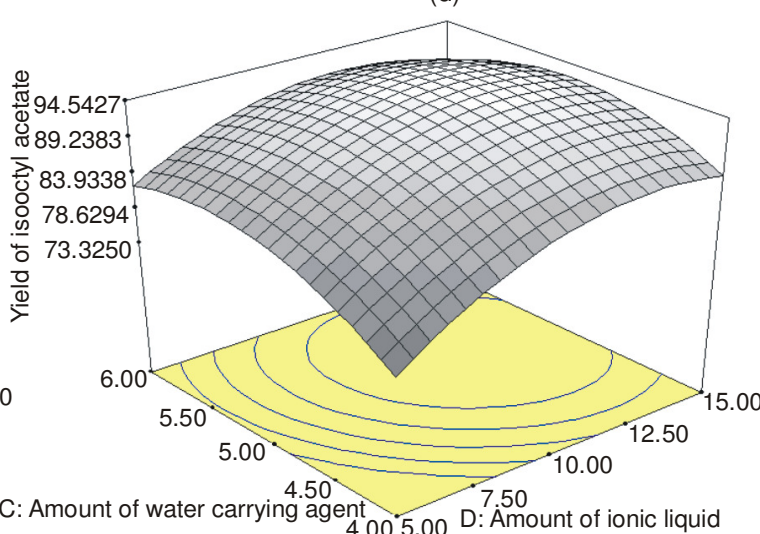

(f)

Fig. 3. Response surface plots showing the predicted values of yield of isooctyl acetate: effect of reaction time and acid/alcohol molar ratio (a), reaction time and amount of water carrying agent (b), reaction time and amount of ionic liquid (c), acid/alcohol molar ratio and amount of water carrying agent (d), acid/alcohol molar ratio and amount of ionic liquid (e) and amount of ionic liquid and amount of water carrying agent (f) on yield of isooctyl acetate. Other variables are held at constant level

reaction. There was almost no interaction between reaction time and alcohol/acid ratio, the relatively circular nature of the contour curve was evident. From the 3D-plot, we could see that yield of iso-octyl acetate was almost dependent on reaction time and alcohol/acid ratio. The yield increased gradually to the peak value with a little time and then decreased with the increase of the molar ratio at a fixed amount of water carrying agent and amount of catalyst.

Plots of yield of iso-octyl acetate as a function of the reaction time and amount of water carrying agent were presented in Figs. $2 b$ and $3 b$. The elliptical nature of the contour plot between the reaction time and amount of water carrying agent indicated that a significant mutual interaction had an effect on the conversion to iso-octyl acetate. It meant that amount of water carrying agent exhibited a most significant influence on the response surface. It is suggested that the yield of iso-octyl acetate was dependent of both the reaction time and amount of water carrying agent. The maximum yield exceeded $95 \%$ with increasing the reaction time and amount of water carrying agent and thereafter decreased.

The interaction between reaction time and amount of ionic liquid, acid/alcohol molar ratio and amount of water carrying agent were presented in Figs. 2c, 3c and 2d, 3d, respectively. The saddle point nature of the contour plots indicated that the stationary point located inside the experimental region and the yield of iso-octyl acetate was likely to be affected by the interaction variables. At initial time, the yield of iso-octyl acetate increased with increasing mount of ionic liquid, which 
reflected a general effect of ascending mount of catalyst on the reaction rate. Similar tendency was observed in the relationship between acid/alcohol molar ratio and amount of water carrying agent.

Figs. 2e and 3e presented contour plot and 3D-plot of the effect of the acid/alcohol molar ratio and amount of ionic liquid on the reaction. A moderate interaction between the acid/alcohol molar ratio and amount of ionic liquid from the elliptical nature of the contour plot also had an effect on the conversion to isooctyl acetate. The maximum yield of iso-octyl acetate was obtained with increasing the acid/alcohol molar ratio and amount of ionic liquid and thereafter decreased.

Figs. $2 \mathrm{f}$ and $3 \mathrm{f}$ represented the interaction between amount of water carrying agent and amount of ionic liquid. From the analysis of the response surface plots, amount of ionic liquid also showed a significant influence on the response surface.

Determination of the optimum condition: In this work, RSM was used to optimize for obtaining the highest yield of iso-octyl acetate. The results showed that the model was significant and it was fitted to evaluate the effect of variable. Based on multiple regression equation, the optimum process condition was found to be: acid/alcohol molar ratio of 1:1.82, amount of water carrying agent of $11.75 \mathrm{~mL}$, amount of catalyst of 5.17 wt. \% and reaction time of $1.55 \mathrm{~h}$. Under such condition, the yield of iso-octyl acetate was reached a maximum of 95.78 $\%$. The optimum parameters were converted as follows: acid/ alcohol molar ratio of $1: 1.8$, amount of water carrying agent of $12 \mathrm{~mL}$, amount of catalyst of $5 \mathrm{wt}$. \% and reaction time of $1.6 \mathrm{~h}$. This set of optimum parameters got a maximum of 95.35 $\%$ yield of iso-octyl acetate. Similar theoretical calculations and experimental value showed that actual and predicted data had a good fitness. It also indicated that regression equation could truly reflect effect of four variables on yield of iso-octyl acetate.

Recycling of ionic liquid $\left[\mathrm{HSO}_{3}\right.$-pmim] $\mathrm{HSO}_{4}$ : The main advantage of the ionic liquid catalysts was that it could be recyclable for further use. The stability for $\left[\mathrm{HSO}_{3}-\mathrm{pmim}\right] \mathrm{HSO}_{4}$ was conducted, the results were shown in Fig. 4. After each cycling reaction, the ionic liquid was extracted with toluene and vacuum dried for $5 \mathrm{~h}$ at $120^{\circ} \mathrm{C}$. After vacuum drying, the $\left[\mathrm{HSO}_{3}\right.$-pmim $] \mathrm{HSO}_{4}$ was assessed by ${ }^{1} \mathrm{H}$ NMR spectroscopy,

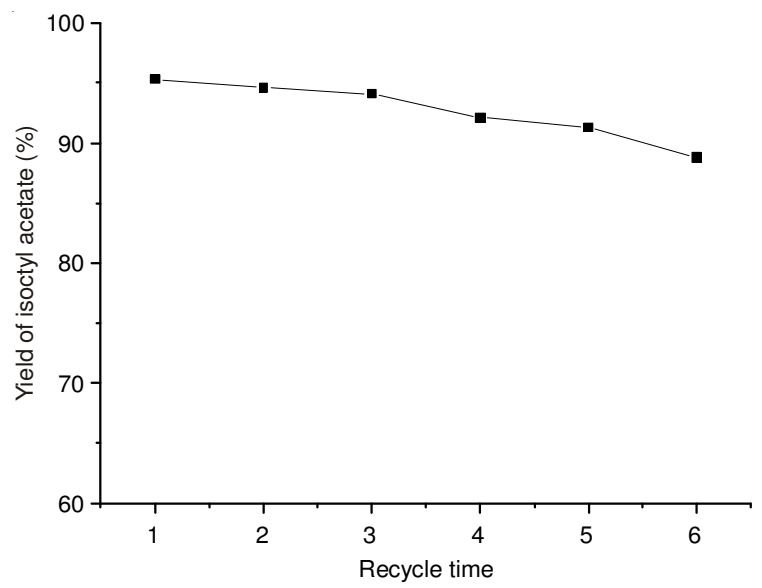

Fig. 4. Catalyst recycling of esterification of acetic acid with iso-octano Reaction conditions: acetic acid $0.18 \mathrm{~mol}$, iso-octanol $0.10 \mathrm{~mol}$, amount of ionic liquid $0.65 \mathrm{~g}, 12 \mathrm{~mL}$ cyclohexane and reflux for $1.6 \mathrm{~h}$ which showed no traces of reactants or products. From Fig. 4 , we found that $\left[\mathrm{HSO}_{3}\right.$-pmim $] \mathrm{HSO}_{4}$ showed best catalytic properties and the yield of iso-octyl acetate was still as high as $88.8 \%$ after five cycles. The slight decrease of conversion might be ascribed to the slight deactivation of ionic liquid.

\section{Conclusion}

$\left[\mathrm{HSO}_{3}\right.$-pmim $] \mathrm{HSO}_{4}$ was used as a catalyst to perform esterification of acetic acid and iso-octanol. Response surface methodology was successfully applied to determine the operation conditions for optimizing the conversion of iso-octanol to iso-octyl acetate. The results showed a significantly good fit to this model and the response evaluated from the quadratic model showed a good agreement with the observed ones. F-test and $\mathrm{P}$ values showed the parameters had very significant influence on the yield of iso-octyl acetate. According to the graphical optimzition in response to surface methodology, the optimum parameters were: amount of water carrying agent of $12 \mathrm{~mL}$, acetic acid to iso-octanol molar ratio of 1.8:1, amount of catalyst of $5 \mathrm{wt}$. \% to iso-octanol and $1.6 \mathrm{~h}$ reaction time. This set of optimum parameters gave a maximum of $95.35 \%$ yield of iso-octyl acetate. $\left[\mathrm{HSO}_{3}\right.$-pmim] $\mathrm{HSO}_{4}$ showed good catalytic activity and stability.

\section{REFERENCES}

1. I.J. Dijs, H.L.F. van Ochten, C.A. van Walree, J.W. Geus and L.W. Jenneskens, J. Mol. Catal. Chem., 188, 209 (2002).

2. A. Heidekum, M.A. Harmer and W.F. Hoelderich, J. Catal., 181, 217 (1999).

3. R.A. Crane, S.H. Brown and L. De Caul, USP 5973193 (1999).

4. K. Sano, M. Nishiyama, T. Suzuki, S. Wakabayashi and K. Miyahara, USP 5189201 (1993)

5. Y.Y. Wang, X.X. Gong, Z.Z. Wang and L.Y. Dai, J. Mol. Catal. Chem., 322, 7 (2010).

6. M. Ghiaci, B. Aghabarari, S. Habibollahi and A. Gil, Bioresour. Technol., 102, 1200 (2011).

7. A.S. Amarasekara and O.S. Owereh, Catal. Commun., 11, 1072 (2010).

8. X.L. Tong and Y.D. Li, ChemSusChem, 3, 350 (2010).

9. J. Fraga-Dubreuil, K. Bourahla, M. Rahmouni, J.P. Bazureau and J. Hamelin, Catal. Commun., 3, 185 (2002).

10. G. Lombardi-Boccia, B. Martínez-Domínguez, A. Aguzzi and F. Rincón-León, Food Chem., 78, 505 (2002).

11. M.S. Tanyildizi, D. Özer and M. Elibol, Process Biochem., 40, 2291 (2005).

12. K.T. Tan, K.T. Lee and A.R. Mohamed, Bioresour. Technol., 101, 965 (2010).

13. C.J. Shieh, H.F. Liao and C.C. Lee, Bioresour. Technol., 88, 103 (2003).

14. X.X. Han and L.X. Zhou, Chem. Eng. J., 172, 459 (2011).

15. X. D. Wu, X. X. Han, L. X. Zhou and A. Li, Indian J. Chem., 51A, 791 (2012).

16. H. Xing, T. Wang, Z. Zhou and Y. Dai, Ind. Eng. Chem. Res., 44, 4147 (2005).

17. E. Martendal, D. Budziak and E. Carasek, J. Chromatogr. A, 1148, 131 (2007).

18. R.H. Myers and U.S.A. Boston, Allyn and Bacan Inc., pp. 67-125 (1971).

19. G.E.P. Box, W.G. Hunter and J.S. Hunter, John Wiley \& Sons, New York, pp. 291-334 (1978). 